\title{
Associations of LRP5 and MTHFR Gene Variants With Osteoarthritis Prevalence in General Elderly Women: A Japanese Cohort Survey Randomly Sampled From a Basic Resident Registry
}

\author{
Masaki Nakano \\ Shinshu University \\ Haruka Yui \\ Shinshu University \\ Shingo Kikugawa \\ DNA Chip Research (Japan) \\ Ryosuke Tokida \\ Shinshu University \\ Noriko Sakai \\ Nagano Children's Hospital \\ Naoki Kondo \\ Niigata University \\ Naoto Endo \\ Niigata University \\ Hirotaka Haro \\ University of Yamanashi \\ Hiroki Shimodaira \\ Shinshu University \\ Takako Suzuki \\ Tokyo Kasei Gakuin University \\ Hiroyuki Kato \\ Shinshu University \\ Jun Takahashi \\ Shinshu University \\ Yukio Nakamura ( $\nabla$ yxn14@aol.jp ) \\ Shinshu University
}

Research Article 
Keywords: genetic variant, LRP5, MTHFR, osteoarthritis, osteoporosis

Posted Date: January 8th, 2021

DOI: https://doi.org/10.21203/rs.3.rs-137552/v1

License: (c) (1) This work is licensed under a Creative Commons Attribution 4.0 International License. Read Full License 


\section{Abstract}

Osteoarthritis (OA) is a common and degenerative joint disorder in the elderly. A greater importance of understanding the relationship between genetic factors and OA prevalence has emerged with population aging. We therefore investigated the associations of several bone disease-related genetic variants with the prevalence of OA and osteoporosis in Japanese elderly women from the Obuse study cohort, which was randomly sampled from a basic town resident registry. In total, 206 female participants (mean \pm standard deviation age: $69.7 \pm 11.0$ years) who completed OA, bone mineral density, and genotype assessments were included. The number of patients diagnosed as having knee/hip OA and osteoporosis was $59(28.6 \%)$ and 30 (14.6\%), respectively. Fisher's exact testing revealed significant relationships between the minor T allele of $L D L$ receptor related protein $5(L R P 5)$ rs3736228 and the prevalences of knee/hip OA and osteoporosis. The respective odds ratios (ORs) of the TT genotype for knee/hip OA and osteoporosis were 7.28 (95\% confidence interval [Cl] 2.22-28.08) and 5.24 (95\% Cl 0.95-26.98). An additional subgroup analysis for knee OA revealed that the frequency of the common $\mathrm{C}$ allele of methylenetetrahydrofolate reductase (MTHFR) rs 1801133 had a statistically significant protective association with the prevalence of knee OA (OR $0.58,95 \% \mathrm{Cl} 0.35-0.97)$. In sum, the present study demonstrated significant associations of LRP5 rs3736228 and MTHFR rs 1801133 with knee/hip OA and osteoporosis prevalences and knee OA prevalence, respectively, in Japanese elderly women. These results will help further the understanding of OA pathogenesis and related genetic risk factors.

\section{Introduction}

Osteoarthritis $(\mathrm{OA})$ is a common degenerative joint disorder occurring with age whose pathophysiology remains incompletely understood. At present, almost all non-surgical treatment options for OA are limited to analgesis and improving joint movement, with no fundamental cures ${ }^{1}$. Osteoporosis is a widespread metabolic skeletal disease characterized by diminished bone mineral density (BMD) or bone strength, which increases the risk of fractures. Although several effective medications exist ${ }^{2}$, both osteoporosis and $\mathrm{OA}$ are becoming major worldwide health concerns with population aging and rising health-care costs. Therefore, understanding the genetic risk factors for these disorders has emerged as an important issue for disease prevention and therapeutic management.

Many studies on the association of genetic factors with OA and osteoporosis have been reported to date. In the present day, the relationships among genetic variants and related disorders are generally investigated by genome-wide association studies (GWAS). Regarding the prevalence of OA and osteoporosis, 256 and 22 records, respectively, were found in the GWAS catalog (https://www.ebi.ac.uk/gwas/) ${ }^{3}$. Several gene polymorphisms appear to affect OA as well as osteoporosis; indeed, we very recently uncovered a novel association between a homocysteine metabolism-related methylenetetrahydrofolate reductase (MTHFR) C677T variant (rs1801133), which was reportedly related to osteoporosis, with the progression of spinal OA [under review]. 
We have recently established a new population-based epidemiological study of Japanese people that employs random sampling from the basic resident registry of Obuse, a rural town in Japan ${ }^{4,5}$. The Obuse study contains detailed medical information on the community-dwelling elderly population with minimized selection bias, which allows for examination of a cohort representative of the general population. The present study aimed to investigate the associations of several reported bone diseaserelated genetic variants, including MTHFR rs1801133, with the prevalence of OA and osteoporosis in elderly women sampled from the Obuse study cohort. Significant associations were seen for $L D L$ receptor related protein 5 (LRP5) rs3736228 and MTHFR rs1801133 with the prevalences of knee/hip OA and osteoporosis and knee OA, respectively, in Japanese elderly women.

\section{Methods}

The protocol of this study was approved by the investigational review board of Shinshu University Hospital, Japan (approval number: 2792). The research procedure was carried out in accordance with the ethical guidelines of the 2013 Declaration of Helsinki. Written informed consent was provided by all participants prior to the initiation of the study.

\section{Study subjects}

The Obuse study was launched in October 2014 for epidemiological data collection until June 2017. The study randomly sampled 1297 male and female individuals from 5352 members of the resident population between 50-89 years of age in the basic resident registry of Obuse town (Nagano Prefecture, Japan) as a joint collaboration with the cooperating town office. In total, 203 male and 212 female participants provided written informed consent and were enrolled in the Obuse study. The present investigation included 206 female subjects who completed assessments of knee and hip OA, BMD measurements of the total hips and lumbar spine, and genotype determination of the gene variants of interest.

\section{Assessment of OA and osteoporosis}

$\mathrm{OA}$ of the knee and hip was assessed by radiographic examination. The degree of degeneration was evaluated in accordance with the Kellgren-Lawrence (KL) grading system ${ }^{6}$. Radiographs were examined by 2 experienced orthopaedic surgeons (H.S. and Y.N.). The subjects with the worst $K L$ grading of $\geq 3$ in either side of the knees or hips or who had undergone arthroplasty for OA were judged as OA patients. BMD at the lumbar spine and hips was measured using dual-energy X-ray absorptiometry (DXA; PRODIGY, GE Healthcare, Chicago, IL). The regions of interest for lumbar and hip BMD were the L2-4 spinal and bilateral total hip regions, respectively. Subjects with BMD values of $\leq 70 \%$ of the young adult mean (YAM) for either the lumbar region or total hips were diagnosed as having osteoporosis.

\section{Determination of genetic variants}


Cell-free DNA (cfDNA) was extracted from plasma samples of study subjects using a QIAamp Circulating Nucleic Acid Kit (Qiagen, Venlo, Netherlands) according to the manufacturer's instructions. Genotyping assays were performed by a droplet digital polymerase chain reaction (ddPCR) QX200 system (Bio-Rad, Hercules, CA). Reaction mixture aliquots of $20 \mu \mathrm{L}$ containing $10 \mu \mathrm{L} 2 \times$ ddPCR Supermix, $5 \mu \mathrm{L}$ cfDNA sample, and $0.5 \mu \mathrm{L} 40 \times$ TaqMan SNP Genotyping Assay for each variant (Applied Biosystems, Waltham, MA) were prepared. The droplets were generated with a QX200 droplet generator and carefully transferred to $96-$ well PCR plates. After PCR cycling ( 40 cycles of $94^{\circ} \mathrm{C}$ for $30 \mathrm{~s}$ and $60^{\circ} \mathrm{C}$ for $1 \mathrm{~min}$ ), the fluorescence of each droplet was determined using a QX200 droplet reader followed by analysis with QuantaSoft version 1.7.4 software (Bio-Rad). The present study examined the following genetic variants: LRP5 rs312009 and rs3736228, growth differentiation factor 5 (GDF5) rs143383, SMAD family member 3 (SMAD3) rs12901499, and MTHFR rs1801133.

\section{Statistical analysis}

The background characteristic data of each study group (healthy control, OA, osteoporosis, and comorbid with $\mathrm{OA}$ and osteoporosis) are presented as the mean \pm standard deviation (SD) together with the median value. Fisher's exact test was performed to calculate the odds ratio (OR) and $95 \%$ confidence interval (Cl) of variant genotypes and alleles for the prevalences of $\mathrm{OA}$ and osteoporosis versus healthy controls using R version 3.4 software ${ }^{7}$. A two-tailed $P$-value of $<0.05$ was considered statistically significant in this study.

\section{Results}

\section{Background characteristics of study subjects}

The average \pm SD age of the 206 female subjects at enrollment was $69.7 \pm 11.0$ years. The number of patients diagnosed as having OA and osteoporosis was 51 (24.8\%; knee: 40, hip: 3, knee and hip: 8) and 22 (10.7\%), respectively. Eight patients (3.9\%) suffered from both osteoporosis and OA (knee: 6, hip: 1, knee and hip: 1) and were classified into the comorbid group. One hundred and twenty-five subjects having neither OA nor osteoporosis were defined as healthy controls in this study. The background characteristics of the study groups are summarized in Table 1.

\section{Associations of genotype and allele frequencies with $\mathrm{OA}$ and osteoporosis}

In the present cohort, we observed no remarkable associations for LRP5 rs312009, GDF5 rs 143383 , or SMAD3 rs12901499 with OA or osteoporosis prevalence (Tables 2, 3 and Figures 1, 2). In contrast, the minor T allele of $\angle R P 5$ rs3736228 and its homozygotic genotype showed significant relationships with the prevalence rate of knee/hip OA. The ORs of the TT genotype and T allele for OA compared with healthy controls were $7.28(95 \% \mathrm{Cl} 2.22-28.08 ; P<0.001)$ and $1.80(95 \% \mathrm{Cl} 1.07-3.00 ; P<0.05)$, respectively (Table 2 and Figure 1). Although not significantly, the common $\mathrm{C}$ allele of MTHFR rs 1801133 tended to protect against knee/hip OA prevalence. The respective ORs of the $\mathrm{CC}$ genotype and $\mathrm{C}$ allele for OA were $0.55(95 \% \mathrm{Cl} 0.23-1.22 ; P=0.15)$ and $0.70(95 \% \mathrm{Cl} 0.43-1.14 ; P=0.13)$ versus the healthy 
control group (Table 2 and Figure 1). The prevalence rate of osteoporosis was significantly correlated with the TT genotype of $\angle R P 5$ rs3736228 (OR 5.24, 95\% Cl 0.95-26.98; $P<0.05$ ) (Table 3 and Figure 2).

\section{Subgroup analysis for knee OA prevalence}

In a subgroup analysis, we focused on the prevalence of knee $O A$, which was the most common disorder witnessed in this study. In knee OA only or knee OA + comorbid osteoporosis patients, both the TT genotype $(P<0.001)$ and T allele $(P<0.05)$ of $L R P 5$ rs3736228 associated significantly with knee OA prevalence as compared with healthy controls (Table 4). Moreover, the $C$ allele of MTHFR rs 1801133 demonstrated a statistically significant protective association with the prevalence rate of knee OA (OR $0.58,95 \% \mathrm{Cl} 0.35-0.97 ; P<0.05)$ in the knee OA + comorbid osteoporosis subgroup (Table 4).

\section{Discussion}

This study demonstrated a significant relationship between $L R P 5$ rs3736228 and the skeletal disorders of $\mathrm{OA}$ and osteoporosis in elderly community-dwelling female residents randomly sampled from a Japanese town resident registry. A statistically significant protective association of the common allele of MTHFR rs1801133 with knee OA prevalence was also observed. As the population sampling of our cohort minimized selection bias, our results might be considered reflective of the Japanese general population.

LRP5 and 6 (LRP5/6) are required as co-receptors for canonical Wnt signaling ${ }^{8,9}$ and play important roles in skeletal development and metabolism. A number of $\angle R P 5$ gene variants have been reported. Of those, associations of the missense variants $\angle R P 5$ rs3736228 (Ala1330Val) and rs4988321 (Val667Met) with decreased $B M D$ and the risk of osteoporotic fracture are well described ${ }^{10,11}$. In particular, a relationship between LRP5 A1330V and diminished BMD has been identified in the Japanese population ${ }^{12,13}$. A loss of function in LRP5 increased cartilage degradation in a mouse model ${ }^{14}$ and was also suggested to be associated with OA. However, little is known on the precise connection between OA and LRP5 gene variants. Although associations of $\angle R P 5$ rs 41494349 (Gln89Arg) with spinal OA ${ }^{15}$ and $L R P 5$ rs3736228 with knee $O A^{16}$ have been reported, no information has been recorded in the GWAS catalog to date (https://www.ebi.ac.uk/gwas/) ${ }^{3}$. Therefore, the findings of this study demonstrating a relationship between the T allele of $\angle R P 5$ rs3736228 and knee/hip OA prevalence in a randomly sampled population cohort will be of value for further understanding the relationship between OA development and the pathophysiological role of LRP5 dysfunction.

In the subgroup analysis for knee $\mathrm{OA}$, there was a protective association for the common $\mathrm{C}$ allele of MTHFR rs1801133 (Ala222Val) rather than a risk association of the minor T allele with the prevalence rate of knee OA. MTHFR is known to act within the methionine cycle and play an essential role in homocysteine clearance. A functional deficiency of the MTHFR enzyme leads to mild elevation of circulating homocysteine levels ${ }^{17}$. The $\mathrm{A} 222 \mathrm{~V}$ missense variant is a common mutation in the MTHFR gene that causes dysfunctional enzymatic activity. Notably, the T allele of MTHFR rs1801133 has been implicated in decreased BMD and the occurrence of osteoporotic fractures ${ }^{18,19}$, and we very recently 
uncovered a relationship among homocysteine, MTHFR rs1801133, and spinal OA in Japanese postmenopausal women [under review]. The results of the present study imply a correlation between diminished homocysteine levels and a lower risk of knee OA prevalence. Since circulating homocysteine levels can be decreased by vitamin B group supplementation ${ }^{20}$, the significance of B-vitamins intervention in individuals bearing the T allele of MTHFR rs1801133 for preventing OA development may warrant further investigation.

An intron variant of $\angle R P 5$ gene rs312009 as well as GDF5 rs143383 and SMAD3 rs12901499 showed no remarkable correlations with $\mathrm{OA}$ or osteoporosis prevalence in this study. The rs 143383 is located in the 5 -untranslated region core promotor of GDF5, which encodes a chondrogenic protein. A relationship of rs143383 with OA has been demonstrated in various racial groups, including a Japanese cohort ${ }^{21,22}$. On the other hand, SMAD3 is a member of the SMAD family of proteins and plays an essential role in mediating the transforming growth factor-beta signaling pathway. A genetic variant, rs12901499, within the intron 1 of $S M A D 3$ is reportedly associated with $O A$ in Caucasian and Asian populations ${ }^{23,24}$. However, other studies have shown no relationship for either GDF5 rs143383 or SMAD3 rs 12901499 with OA prevalence ${ }^{25,26}$. Relatively small number of samples limited to female subjects is a limitation of the current study. Besides, although the subjects were randomly sampled from a resident registry, there was a potential for selection bias due to the low participation rate (32.0\%) as a result of the noncompulsory survey design. Furthermore, since it sampled from a single town in Japan, this study might contain local features that should be considered when interpreting the data. Future studies with larger sample sizes and male subjects that include multiple regions in Japan and/or other Asian countries will overcome the controversial issues.

In conclusion, we observed significant associations of LRP5 rs3736228 and MTHFR rs1801133 with knee/hip OA and osteoporosis prevalences and knee OA prevalence, respectively, in Japanese elderly women from the randomly sampled Obuse study cohort. The results of the present study will help further the understanding of OA pathogenesis and related genetic risk factors, which will contribute to improved disease prevention and therapeutic management.

\section{Data availability statements}

The data analyzed and/or generated during the current study are available from the corresponding author on reasonable request.

\section{Declarations}

\section{Acknowledgements}

This work was supported by a grant from the JOA-Subsidized Science Project Research 2018-2020 to Y.N. We would like to thank Dr. Takashi Igarashi of the Center for Clinical Research at Shinshu University Hospital, Dr. Hironobu Sato of the Obuse Town Institute for Community Health Promotion, and the Obuse 
Town Office for sample selection in this study. Our gratitude extends to Mr. Trevor Ralph for English language editing as well as all participants in the present study.

\section{Author contributions}

Y.N. directed and designed the study. M.N., H.Y., S.K., R.T., and N.S. analyzed the data and performed the statistical analysis. N.K., N.E., H.H., H.S., T.S., H.K., J.T., and Y.N. interpreted the data. M.N., H.Y., S.K., and Y.N. drafted the manuscript. All authors approved the final version of the manuscript for publication.

\section{Competing interests}

The authors declare no competing interests related to this work.

\section{References}

1. Hunter DJ, Bierma-Zeinstra S. Osteoarthritis. Lancet 2019 Apr 27;393(10182):1745-59.

2. Ensrud KE, Crandall CJ. Osteoporosis. Ann Intern Med 2017 Aug 1;167(3):ITC17-32.

3. Welter D, MacArthur J, Morales J, Burdett T, Hall P, Junkins H, Klemm A, Flicek P, Manolio T, Hindorff L, Parkinson H. The NHGRI GWAS Catalog, a curated resource of SNP-trait associations. Nucleic Acids Res 2014 Jan;42(Database issue):D1001-6.

4. Uehara M, Takahashi J, Ikegami S, Tokida R, Nishimura H, Sakai N, Kato H. Sagittal spinal alignment deviation in the general elderly population: a Japanese cohort survey randomly sampled from a basic resident registry. Spine J 2019 Feb;19(2):349-56.

5. Tokida R, Ikegami S, Takahashi J, Ido Y, Sato A, Sakai N, Horiuchi H, Kato H. Association between musculoskeletal function deterioration and locomotive syndrome in the general elderly population: a Japanese cohort survey randomly sampled from a basic resident registry. BMC Musculoskelet Disord 2020 Jul 3;21(1):431.

6. Ball J, Jeffrey MR, Kellgren JH, Eds. The epidemiology of chronic rheumatism: Atlas of standard radiographs of arthritis. Blackwell Scientific Publications, Oxford, UK. 1963.

7. R Core Team. R: A language and environment for statistical computing. R Foundation for Statistical Computing, Vienna, Austria. 2017. https://www.r-project.org/.

8. Tamai K, Semenov M, Kato Y, Spokony R, Liu C, Katsuyama Y, Hess F, Saint-Jeannet JP, He X. LDLreceptor-related proteins in Wnt signal transduction. Nature 2000 Sep 28;407(6803):530-5.

9. Pinson KI, Brennan J, Monkley S, Avery BJ, Skarnes WC. An LDL-receptor-related protein mediates Wnt signalling in mice. Nature 2000 Sep 28;407(6803):535-8.

10. van Meurs JB, Trikalinos TA, Ralston SH, Balcells S, Brandi ML, Brixen K, Kiel DP, Langdahl BL, Lips P, Ljunggren O, Lorenc R, Obermayer-Pietsch B, Ohlsson C, Pettersson U, Reid DM, Rousseau F, Scollen S, Van Hul W, Agueda L, Akesson K, Benevolenskaya LI, Ferrari SL, Hallmans G, Hofman A, Husted LB, Kruk M, Kaptoge S, Karasik D, Karlsson MK, Lorentzon M, Masi L, McGuigan FE, Mellström D, Mosekilde L, Nogues X, Pols HA, Reeve J, Renner W, Rivadeneira F, van Schoor NM, Weber K, 
Ioannidis JP, Uitterlinden AG; GENOMOS Study. Large-scale analysis of association between LRP5 and LRP6 variants and osteoporosis. JAMA 2008 Mar 19;299(11):1277-90.

11. Richards JB, Rivadeneira F, Inouye M, Pastinen TM, Soranzo N, Wilson SG, Andrew T, Falchi M, Gwilliam R, Ahmadi KR, Valdes AM, Arp P, Whittaker P, Verlaan DJ, Jhamai M, Kumanduri V, Moorhouse M, van Meurs JB, Hofman A, Pols HA, Hart D, Zhai G, Kato BS, Mullin BH, Zhang F, Deloukas P, Uitterlinden AG, Spector TD. Bone mineral density, osteoporosis, and osteoporotic fractures: a genome-wide association study. Lancet 2008 May 3;371(9623):1505-12.

12. Ezura Y, Nakajima T, Urano T, Sudo Y, Kajita M, Yoshida H, Suzuki T, Hosoi T, Inoue S, Shiraki M, Emi M. Association of a single-nucleotide variation (A1330V) in the low-density lipoprotein receptorrelated protein 5 gene (LRP5) with bone mineral density in adult Japanese women. Bone 2007 Apr;40(4):997-1005.

13. Urano T, Shiraki M, Usui T, Sasaki N, Ouchi Y, Inoue S. A1330V variant of the low-density lipoprotein receptor-related protein 5 (LRP5) gene decreases Wnt signaling and affects the total body bone mineral density in Japanese women. Endocr J 2009;56(4):625-31.

14. Lodewyckx L, Luyten FP, Lories RJ. Genetic deletion of low-density lipoprotein receptor-related protein 5 increases cartilage degradation in instability-induced osteoarthritis. Rheumatology (Oxford) 2012 Nov;51(11):1973-8.

15. Urano T, Shiraki M, Narusawa K, Usui T, Sasaki N, Hosoi T, Ouchi Y, Nakamura T, Inoue S. Q89R polymorphism in the LDL receptor-related protein 5 gene is associated with spinal osteoarthritis in postmenopausal Japanese women. Spine (Phila Pa 1976) 2007 Jan 1;32(1):25-9.

16. Yerges-Armstrong LM, Yau MS, Liu Y, Krishnan S, Renner JB, Eaton CB, Kwoh CK, Nevitt MC, Duggan DJ, Mitchell BD, Jordan JM, Hochberg MC, Jackson RD. Association analysis of BMD-associated SNPs with knee osteoarthritis. J Bone Miner Res 2014 Jun;29(6):1373-9.

17. Moll S, Varga EA. Homocysteine and MTHFR mutations. Circulation 2015 Jul 7;132(1):e6-9.

18. Bathum L, von Bornemann Hjelmborg J, Christiansen L, Madsen JS, Skytthe A, Christensen K. Evidence for an association of methylene tetrahydrofolate reductase polymorphism C677T and an increased risk of fractures: results from a population-based Danish twin study. Osteoporos Int 2004 Aug;15(8):659-64.

19. Shiraki M, Urano T, Kuroda T, Saito M, Tanaka S, Miyao-Koshizuka M, Inoue S. The synergistic effect of bone mineral density and methylenetetrahydrofolate reductase (MTHFR) polymorphism (C677T) on fractures. J Bone Miner Metab 2008;26(6):595-602.

20. Collaboration HLT. Lowering blood homocysteine with folic acid based supplements: meta-analysis of randomised trials. Homocysteine Lowering Trialists' Collaboration. BMJ 1998 Mar 21;316(7135):894-8.

21. Miyamoto Y, Mabuchi A, Shi D, Kubo T, Takatori Y, Saito S, Fujioka M, Sudo A, Uchida A, Yamamoto S, Ozaki K, Takigawa M, Tanaka T, Nakamura Y, Jiang Q, Ikegawa S. A functional polymorphism in the 5' UTR of GDF5 is associated with susceptibility to osteoarthritis. Nat Genet 2007 Apr;39(4):529-33. 
22. Chapman K, Takahashi A, Meulenbelt I, Watson C, Rodriguez-Lopez J, Egli R, Tsezou A, Malizos KN, Kloppenburg M, Shi D, Southam L, van der Breggen R, Donn R, Qin J, Doherty M, Slagboom PE, Wallis G, Kamatani N, Jiang Q, Gonzalez A, Loughlin J, Ikegawa S. A meta-analysis of European and Asian cohorts reveals a global role of a functional SNP in the 5' UTR of GDF5 with osteoarthritis susceptibility. Hum Mol Genet 2008 May 15;17(10):1497-504.

23. Valdes AM, Spector TD, Tamm A, Kisand K, Doherty SA, Dennison EM, Mangino M, Tamm A, Kerna I, Hart DJ, Wheeler M, Cooper C, Lories RJ, Arden NK, Doherty M. Genetic variation in the SMAD3 gene is associated with hip and knee osteoarthritis. Arthritis Rheum 2010 Aug;62(8):2347-52.

24. Yang HY, Hu WH, Jiang T, Zhao H. SMAD3 gene rs12901499 polymorphism increased the risk of osteoarthritis. Biosci Rep 2018 May 15;38(3):BSR20180380.

25. Tsezou A, Satra M, Oikonomou P, Bargiotas K, Malizos KN. The growth differentiation factor 5 (GDF5) core promoter polymorphism is not associated with knee osteoarthritis in the Greek population. J Orthop Res 2008 Jan;26(1):136-40.

26. Hong JQ, Wang YX, Li SH, Jiang GY, Hu B, Yang YT, Meng JH, Yan SG. Association between SMAD3 gene polymorphisms and osteoarthritis risk: a systematic review and meta-analysis. J Orthop Surg Res 2018 Sep 12;13(1):232.

\section{Tables}

Table 1. Background characteristics of the study groups

\begin{tabular}{|c|c|c|c|c|}
\hline & $\begin{array}{l}\text { Healthy control }(n \\
=125) \\
\text { mean } \pm \text { SD } \\
\text { (median) }\end{array}$ & $\begin{array}{l}\text { Osteoarthritis ( } n \\
=51 \text { ) } \\
\text { mean } \pm \text { SD } \\
\text { (median) }\end{array}$ & $\begin{array}{l}\text { Osteoporosis }(n \\
=22) \\
\text { mean } \pm \text { SD } \\
\text { (median) }\end{array}$ & $\begin{array}{l}\text { Comorbid group }{ }^{\dagger} \\
(n=8) \\
\text { mean } \pm \text { SD } \\
\text { (median) }\end{array}$ \\
\hline Age, years & $64.0 \pm 8.2(64.0)$ & $79.3 \pm 7.8(82.0)$ & $\begin{array}{l}75.1 \pm 10.3 \\
(77.5)\end{array}$ & $83.1 \pm 6.5(84.5)$ \\
\hline Height, cm & $154.0 \pm 6.4(154.5)$ & $\begin{array}{l}148.1 \pm 6.5 \\
(147.2)\end{array}$ & $\begin{array}{l}148.8 \pm 5.1 \\
(147.9)\end{array}$ & $141.7 \pm 4.2(141.3)$ \\
\hline Weight, kg & $53.0 \pm 8.7(53.0)$ & $52.4 \pm 7.1(52.6)$ & $45.2 \pm 7.0(44.8)$ & $44.5 \pm 3.6(45.2)$ \\
\hline $\mathrm{BMI}, \mathrm{kg} / \mathrm{m}^{2}$ & $22.3 \pm 3.4(22.0)$ & $23.9 \pm 2.9(23.6)$ & $20.3 \pm 2.3(20.0)$ & $22.2 \pm 1.8(21.9)$ \\
\hline $\begin{array}{l}\text { Hip BMD, \% } \\
\text { YAM }\end{array}$ & $91.1 \pm 11.1(90.0)$ & $\begin{array}{l}86.4 \pm 12.3 \\
(84.0)\end{array}$ & $69.6 \pm 8.5(67.5)$ & $65.4 \pm 9.8(63.8)$ \\
\hline $\begin{array}{l}\text { Lumbar BMD, \% } \\
\text { YAM }\end{array}$ & $93.6 \pm 13.7(93.0)$ & $\begin{array}{l}100.0 \pm 20.3 \\
(95.0)\end{array}$ & $\begin{array}{l}71.8 \pm 10.4 \\
(69.5)\end{array}$ & $80.5 \pm 10.5(77.0)$ \\
\hline
\end{tabular}

SD, standard deviation; BMI, body mass index; BMD, bone mineral density; YAM, young adult mean

${ }^{\dagger}$ Comorbid with osteoarthritis and osteoporosis 
Table 2. Genotype and allele frequencies in patients with osteoarthritis

\begin{tabular}{|c|c|c|c|c|}
\hline & $\begin{array}{l}\text { Healthy control } \\
(n=125)\end{array}$ & $\begin{array}{l}\text { Osteoarthritis } \\
(n=51)\end{array}$ & OR $(95 \% \mathrm{Cl})$ & $P$-value \\
\hline \multicolumn{5}{|c|}{ LRP5 rs312009 } \\
\hline CC genotype & $69(55.2 \%)$ & $27(52.9 \%)$ & $0.91(0.45-1.85)$ & 0.87 \\
\hline C allele & $190(76.0 \%)$ & $76(74.5 \%)$ & $0.92(0.53-1.64)$ & 0.79 \\
\hline \multicolumn{5}{|c|}{$\angle R P 5$ rs3736228 } \\
\hline TT genotype & $5(4.0 \%)$ & $12(23.5 \%)$ & $7.28(2.22-28.08)$ & $<0.001$ \\
\hline T allele & $68(27.2 \%)$ & $41(40.2 \%)$ & $1.80(1.07-3.00)$ & $<0.05$ \\
\hline \multicolumn{5}{|c|}{ GDF5 rs143383 } \\
\hline TT genotype & $74(59.2 \%)$ & $26(51.0 \%)$ & $0.72(0.35-1.46)$ & 0.40 \\
\hline T allele & $195(78.0 \%)$ & $73(71.6 \%)$ & $0.71(0.41-1.25)$ & 0.22 \\
\hline \multicolumn{5}{|c|}{ SMAD3 rs12901499 } \\
\hline GG genotype & $20(16.0 \%)$ & $13(25.5 \%)$ & $1.79(0.74-4.22)$ & 0.20 \\
\hline G allele & $105(42.0 \%)$ & $46(45.1 \%)$ & $1.13(0.69-1.85)$ & 0.64 \\
\hline \multicolumn{5}{|c|}{ MTHFR rs1801133 } \\
\hline CC genotype & $42(33.6 \%)$ & $11(21.6 \%)$ & $0.55(0.23-1.22)$ & 0.15 \\
\hline C allele & $145(58.0 \%)$ & $50(49.0 \%)$ & $0.70(0.43-1.14)$ & 0.13 \\
\hline
\end{tabular}

$\mathrm{OR}$, odds ratio; $\mathrm{Cl}$, confidence interval; $L R P 5, L D L$ receptor related protein $5 ; G D F 5$, growth differentiation factor 5; SMAD3, SMAD family member 3; MTHFR, methylenetetrahydrofolate reductase

Table 3. Genotype and allele frequencies in patients with osteoporosis 


\begin{tabular}{|c|c|c|c|c|}
\hline & $\begin{array}{l}\text { Healthy control } \\
(n=125)\end{array}$ & $\begin{array}{l}\text { Osteoporosis } \\
(n=22)\end{array}$ & OR $(95 \% \mathrm{Cl})$ & $P$-value \\
\hline \multicolumn{5}{|c|}{ LRP5 rs312009 } \\
\hline CC genotype & $69(55.2 \%)$ & $12(54.5 \%)$ & $0.97(0.36-2.72)$ & 1.00 \\
\hline C allele & $190(76.0 \%)$ & $33(75.0 \%)$ & $0.95(0.43-2.21)$ & 0.85 \\
\hline \multicolumn{5}{|c|}{ LRP5 rs3736228 } \\
\hline TT genotype & $5(4.0 \%)$ & $4(18.2 \%)$ & $5.24(0.95-26.98)$ & $<0.05$ \\
\hline T allele & $68(27.2 \%)$ & $16(36.4 \%)$ & $1.53(0.72-3.14)$ & 0.21 \\
\hline \multicolumn{5}{|c|}{ GDF5 rs143383 } \\
\hline TT genotype & $74(59.2 \%)$ & $11(50.0 \%)$ & $0.69(0.25-1.91)$ & 0.49 \\
\hline T allele & $195(78.0 \%)$ & $32(72.7 \%)$ & $0.75(0.35-1.72)$ & 0.44 \\
\hline \multicolumn{5}{|c|}{ SMAD3 rs12901499 } \\
\hline GG genotype & $20(16.0 \%)$ & $4(18.2 \%)$ & $1.17(0.26-4.08)$ & 0.76 \\
\hline G allele & $105(42.0 \%)$ & $18(40.9 \%)$ & $0.96(0.47-1.92)$ & 1.00 \\
\hline \multicolumn{5}{|c|}{ MTHFR rs 1801133} \\
\hline CC genotype & $42(33.6 \%)$ & $4(18.2 \%)$ & $0.44(0.10-1.46)$ & 0.21 \\
\hline C allele & 145 (58.0\%) & $22(50.0 \%)$ & $0.72(0.36-1.45)$ & 0.33 \\
\hline
\end{tabular}

$\mathrm{OR}$, odds ratio; $\mathrm{Cl}$, confidence interval; $L R P 5, L D L$ receptor related protein $5 ; G D F 5$, growth differentiation factor 5; SMAD3, SMAD family member 3; MTHFR, methylenetetrahydrofolate reductase

Table 4. Subgroup analysis of patients with knee osteoarthritis 


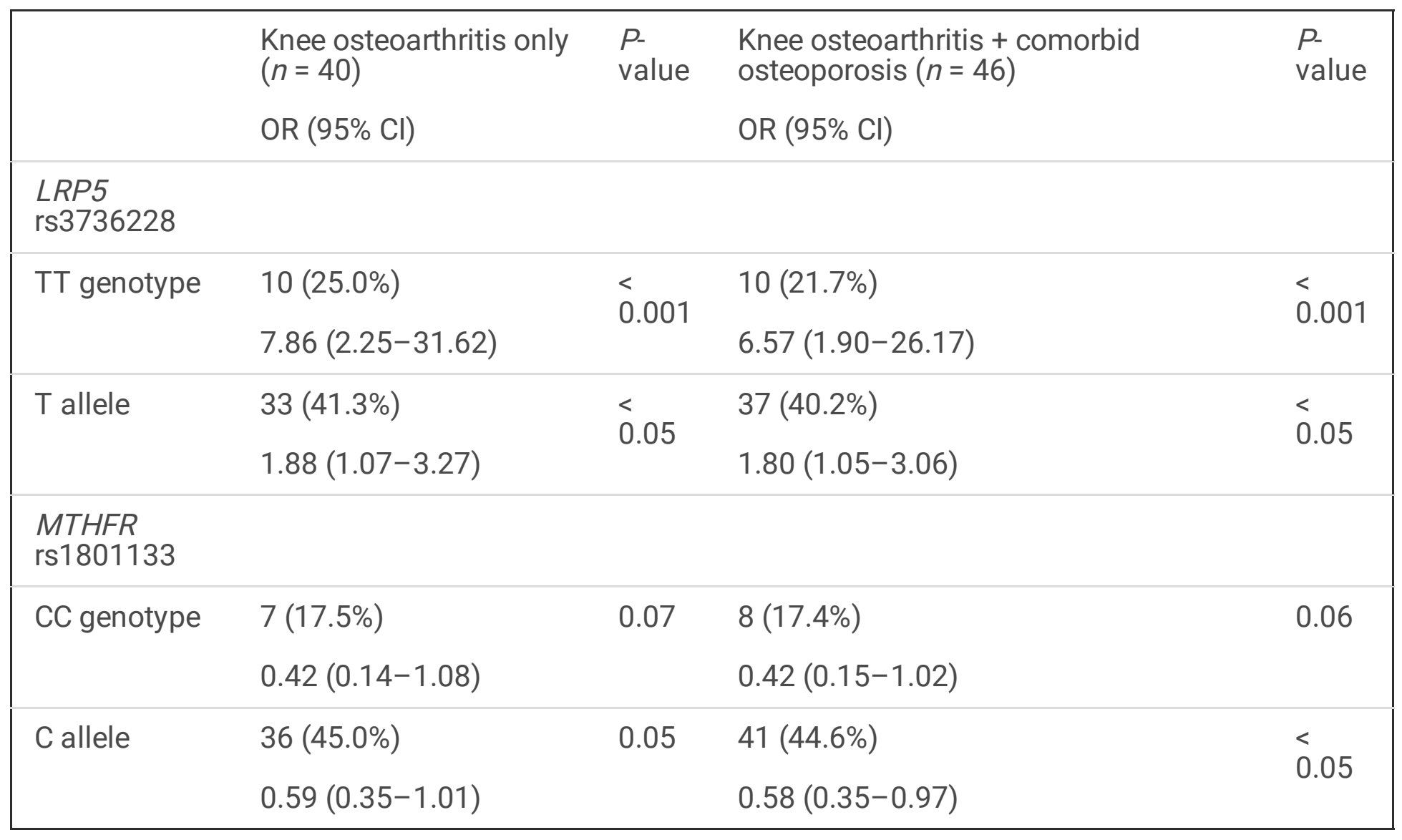

$\mathrm{OR}$, odds ratio; $\mathrm{Cl}$, confidence interval; $L R P 5, L D L$ receptor related protein $5 ; M T H F R$, methylenetetrahydrofolate reductase

\section{Figures}

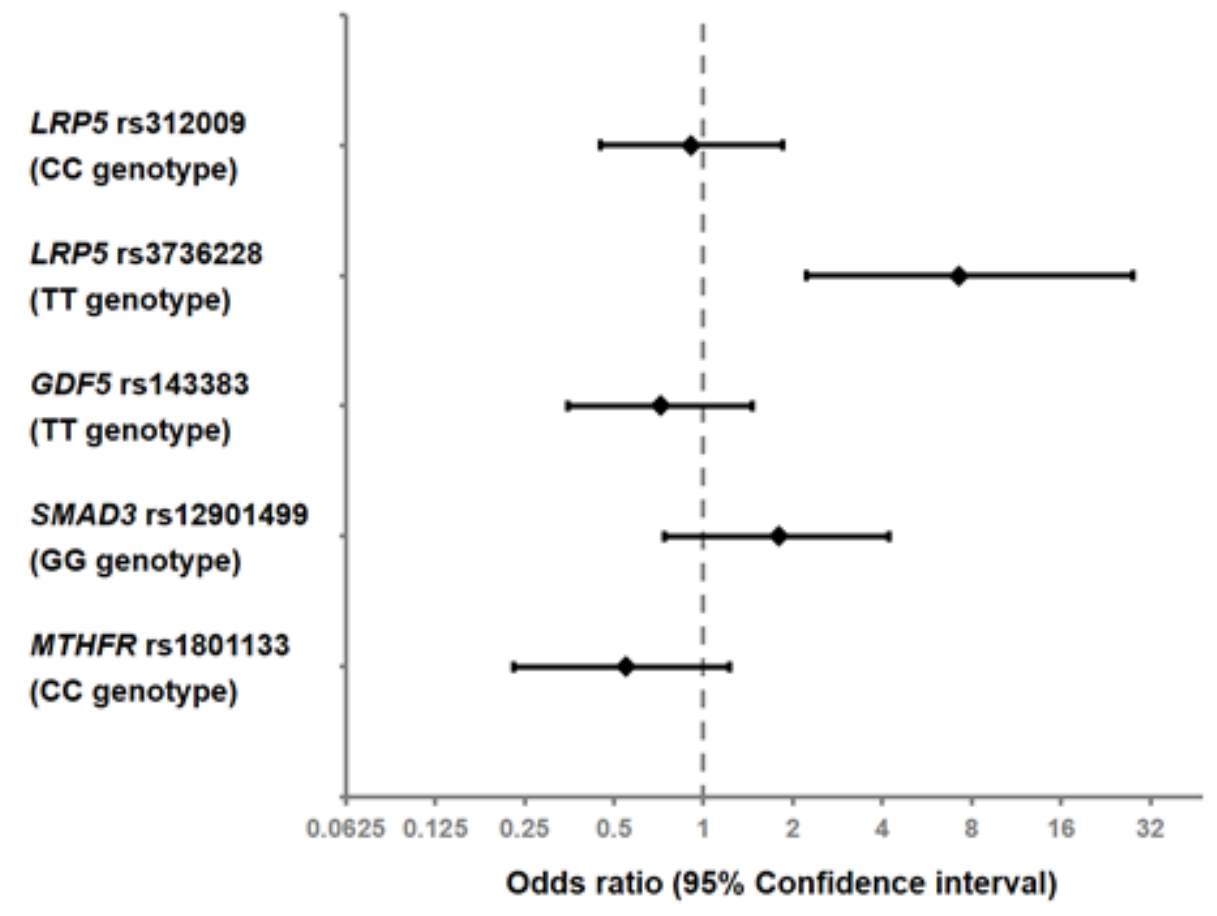


Figure 1

Odds ratios for osteoarthritis by each variant genotype. Fisher's exact test was employed to calculate the odds ratio and $95 \%$ confidence interval of variant genotypes for the prevalence of osteoarthritis versus the healthy control group. LRP5, LDL receptor related protein 5; GDF5, growth differentiation factor 5; SMAD3, SMAD family member 3; MTHFR, methylenetetrahydrofolate reductase

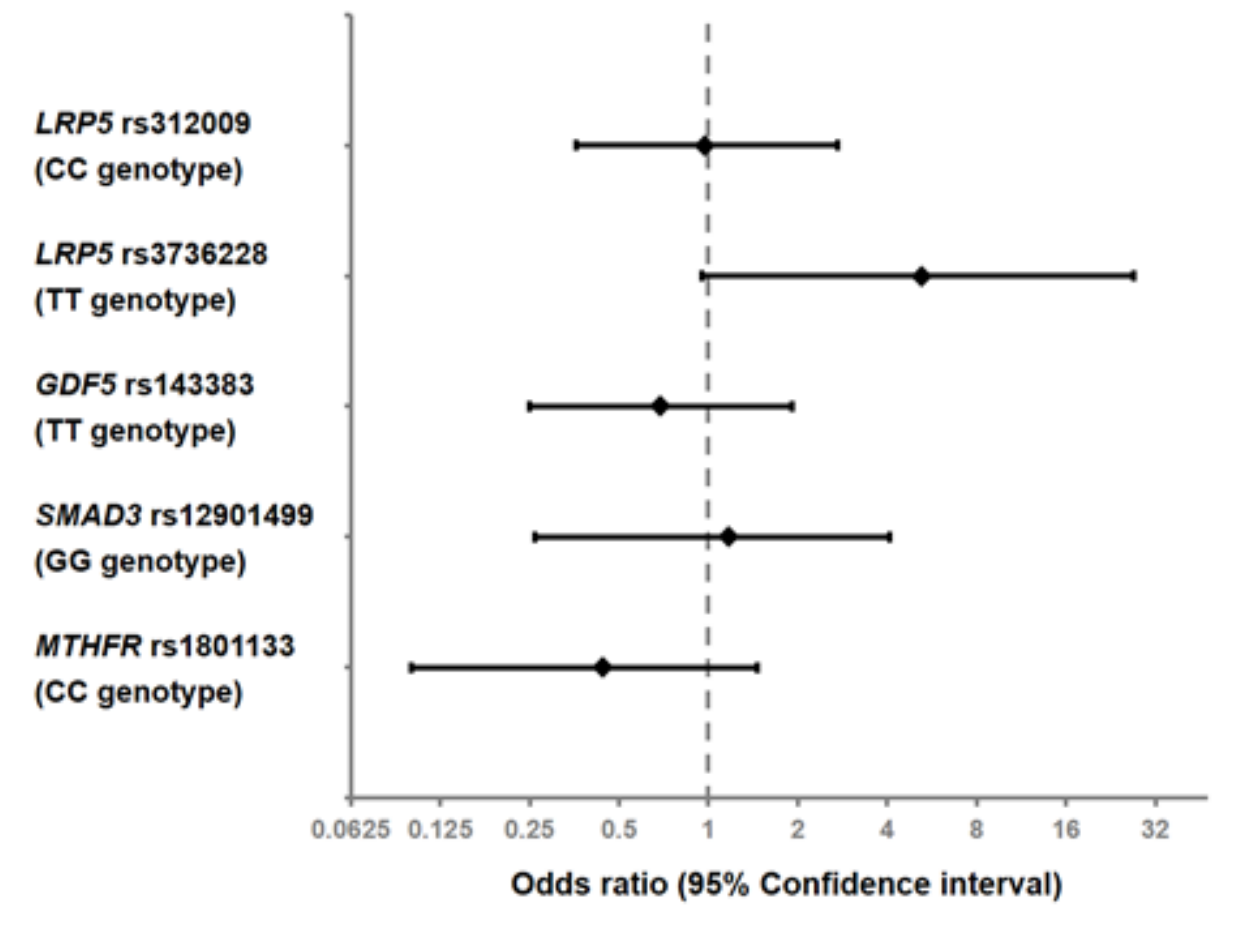

Figure 2

Odds ratios for osteoporosis by each variant genotype. Fisher's exact test was employed to calculate the odds ratio and $95 \%$ confidence interval of variant genotypes for the prevalence of osteoporosis versus the healthy control group. LRP5, LDL receptor related protein 5; GDF5, growth differentiation factor 5; SMAD3, SMAD family member 3; MTHFR, methylenetetrahydrofolate reductase 